\title{
25 Research Soure \\ Comparison of the BOPPPS Model and Traditional Instructional Approaches in Thoracic Surgery Teaching
}

\author{
Kang Hu \\ Weifang Medical University \\ Rui-Jie Ma \\ Shandong University \\ Chao Ma \\ Weifang Medical University \\ Qing-Kang Zheng \\ Weifang Medical University \\ Zhi-Gang Sun ( $\nabla$ sunszg@126.com ) \\ Jinan Central Hospital, Shandong University
}

\section{Research Article}

Keywords: BOPPPS model, traditional instructional approach, thoracic surgery, clinical practice, medical education

Posted Date: June 2nd, 2021

DOI: https://doi.org/10.21203/rs.3.rs-538517/v1

License: (c) (1) This work is licensed under a Creative Commons Attribution 4.0 International License. Read Full License 


\section{Abstract}

Introduction

BOPPPS (bridge-in, learning objective, pretest, participatory learning, posttest, and summary) is a studentcentered modular teaching model that improves classroom teaching effectiveness. This study's primary aim was to explore whether the BOPPPS model has advantages over traditional instructional approaches in teaching lung cancer courses to clinical medical interns.

Methods

A total of 88 students majoring in clinical medicine of Shandong First Medical University and Shandong University, who had clinical practice in thoracic surgery from January 2018 to December 2019, were divided into two groups, receiving the same lung cancer teaching content. The experimental group $(n=44)$ utilized the BOPPPS model, while the control group $(n=44)$ used the traditional instructional approach. A questionnaire was used to attain the students' satisfaction and self-evaluation of the course, and a poststudy examination was used to assess end-of-course performance.

Results

The experimental group's theoretical examination scores with the BOPPPS teaching model were significantly higher than those in the control group. Students can recognize the BOPPPS model more than the traditional instructional approach in course satisfaction, student-teacher interaction, learning initiative, analytical ability, clinical thinking ability, and self-study ability $(p<0.05)$.

Conclusions

Compared with the traditional instructional approach. The BOPPPS model can better inspire clinical medical students' enthusiasm for thoracic surgery and enhance the students' comprehensive ability. In a word, the BOPPPS model has better teaching effectiveness in the clinical teaching practice of thoracic surgery, which is worthy of reference and popularization.

\section{Introduction}

Thoracic surgery is an essential branch of surgery, which has specific particularity. Compared with other branches, thoracic surgery is more professional, facing more complex diseases, and the patient's condition is generally aggressive and critical. Therefore, the requirements for doctors' basic theoretical knowledge and practical ability are very high. At present, clinical medical students have few practical courses in school. There are some problems such as poor operation skills and disconnection between theory and practice after entering clinical practice. It is difficult to improve clinical interns' professional ability in thoracic surgery in a short period. Modern thoracic surgery has been developing continuously, which puts forward higher medical education requirements[1]. 
The traditional instructional approach focuses on lecture-based learning as the teaching center, emphasizing syllabus and concept delivery $[2,3]$. Teachers explain theoretical knowledge, and the students only take notes and accept the knowledge passively [4], while medicine education is complicated and boring $[5,6]$. For undergraduate interns, their theoretical courses are mainly learned through the traditional instructional approach. It is difficult to mobilize students' enthusiasm by using the traditional instructional approach alone in clinical practice [7]. Students' theoretical knowledge is also relatively insufficient, so it is challenging for them to accept teachers' content within a limited time [8]. Combined with the actual clinical practice situation in thoracic surgery, the traditional instructional approach is relatively simple, lacks innovation, cannot stimulate interns' enthusiasm. Hence, it is not easy to achieve exemplary teaching results. Traditional instructional approaches have proved to be not as effective as other teaching strategies in practical application and critical thinking ability [9-11].

The BOPPPS model has initially been proposed by the Center for Teaching and Academic Development, University of British Columbia, Canada [12]. This model emphasizes the student-centered teaching concept and modularizes the classroom teaching process. The BOPPPS model divides the instructional process into six distinct steps: bridge-in, objective, pre-assessment, participatory learning, postassessment, and summary. Teachers can design instructional content, evaluate and revise the instructional process according to these six steps. They also can stimulate students' enthusiasm in learning to actively think and discuss problems. Finally, the students' learning effect is detected and summarized, effectively improving teaching effectiveness.

However, few reports about the application of the BOPPPS model in the clinical teaching of thoracic surgery. This study selected 88 five-year undergraduate students who completed clinical probation in the Department of Thoracic Surgery of our hospital to conduct the research and preliminarily explored the various effects of the BOPPPS model and traditional methods of thoracic surgery teaching.

\section{Methods}

\section{Participants}

The study was conducted with 88 students majoring in Shandong First Medical University and Shandong University's clinical medicine, who had clinical practice in thoracic surgery from January 2018 to December 2019. In 2018, 44 interns in the control group adopted the traditional teaching method. Moreover, in 2019, 44 interns in the experimental group adopted the BOPPPS model. There were 21 females and 23 males in the control group, with an average age of 22.4. The experimental group consisted of 20 males and 24 females, with an average age of 22.5. There was no statistical difference between the two groups in terms of gender, age, entrance achievement, family background, and self-study ability $(p>0.05)$. All the participants signed the informed consent, and the Jinan Central Hospital Affiliated to Shandong University Ethics Committee approved this study of the hospital.

\section{Design}


Both groups of students used the same chapter "lung cancer" as the teaching content. For teaching cases, a lung cancer patient was selected from the inpatients in the department of thoracic surgery. The teacher communicated with the patient in advance and prepared relevant medical data such as patient history, laboratory examination, and imaging examination. The specific teaching methods are as follows.

The control group was mainly taught in the traditional teaching model. The teacher first explained the relevant theoretical knowledge of the selected disease according to the syllabus's specific requirements and then summarized the probation class contents. Then 1 to 2 students asked about the patient's medical history, two students took a physical examination, and each student completed a hospital record.

The experimental group used the BOPPPS model to carry out teaching. One week before the internship, the instructor informed the students of the theoretical chapters and related issues. The BOPPPS model was divided into the following six stages. Bridge-in: According to the teaching content, the teacher connected the content to be learned with the essential knowledge points such as anatomy, pathophysiology, and diagnostics, leading to the focus and application value of the study from the simple to the deep. Learning objective: According to the syllabus, the teacher defined the learning objectives and emphasized the key points and difficulties of teaching. Pretest: The teacher used questionnaires or heuristic questions to test the mastery of theoretical knowledge, which helps adjust the teaching emphasis and teaching methods in the subsequent teaching. Participatory learning: Firstly, the students were divided into groups and selected classic cases according to the discussion's teaching content. Then, a representative of each group was chosen to answer the questions involved in the cases. Finally, the teacher commented on each group's answer results and explained the important and difficult points in the cases. Students can consult textbooks and literature, exchange collected information, and have group discussions. They can also analyze and summarize the questions raised and supplement each other to deepen the impression. Posttest: Students answered and corrected the pretest questions, and the teacher made the core of the posttest according to the problems found in the students' discussion process. Through the posttest to master the students' learning effect on the teaching content, teachers can adjust the teaching plan's difficulty and improve the teaching plan. Summary: Teachers used the flow chart to guide the students to sum up the contents of this lecture, strengthened the key and difficult points, and extended the teaching content. Using the lung cancer chapter in this course as an example, the design of a class is shown in Fig. 1.

\section{Effectiveness assessment}

At the end of the course, the two teaching methods' effectiveness and satisfaction were evaluated in an examination and an anonymous questionnaire.

The theoretical knowledge is in the form of a written examination (a total score of 100 points). The examination questions are randomly selected from the examination question bank, which mainly evaluates the students' knowledge of lung cancer theory. 
Both groups of students participated in the questionnaire survey. Eighty-eight questionnaires were sent out, and eighty-eight were effectively received with an effective recovery rate of $100 \%$. The questionnaire's content mainly includes course satisfaction, student-teacher interaction, learning initiative, analytical ability, clinical thinking ability, and self-study ability. (Likert five-level scoring method is used as the evaluation standard, and $1 \sim 5$ points means completely dissatisfied $\sim$ completely satisfied).

\section{Statistical analysis}

All statistical analyses were performed using the SPSS version 26.0 software. The measurement data were expressed as mean \pm standard deviation ( $x \pm s$ ). Significance was assessed from an independent sample $t$-test. Statistical significance was set as $p<0.05$.

\section{Results}

In the whole teaching process of thoracic surgery, the experimental group students were more active in the learning atmosphere and more active in participating in the internship activities.

\section{Comparison of test scores between the two groups}

As shown in Table 1 and Fig.2, the scores of theoretical examinations in the experimental group under the BOPPPS model were significantly higher than those in the control group (81.4773 $\pm 10.9215>$ $76.3636 \pm 10.6402)$, and the difference was statistically significant $(p<0.05)$.

\section{Comparison of students' satisfaction and self-evaluation between the two groups}

Students recognized the BOPPPS model (experimental group) more than the traditional teaching methods (control group) in terms of course satisfaction, student-teacher interaction, learning initiative, analytical ability, clinical thinking ability, and self-study ability (Fig.3). The difference was statistically significant $(p<0.05)$ (Table 2).

\section{Discussion}

After completing theoretical courses and entering clinical probation, students majoring in clinical medicine often lack a comprehensive understanding of the process of disease diagnosis and treatment, so it is difficult for them to link the theoretical knowledge with clinical practice fully. Traditional teaching methods are mostly simple teacher-led teaching. Thoracic surgery is highly specialized, and the diseases are complex, abstract, and difficult to understand, which often leads students to feel dull, lack enthusiasm, and poor learning effect. Therefore, how to stimulate students' interest in thoracic surgery, improve the clinical teaching effect and optimize the teaching methods are important problems that need to be solved in the current teaching process. The BOPPPS model is a student-centered teaching method and observation system adopted by many famous colleges and universities in Canada in recent years $[12,13]$. This teaching method has incomparable advantages over traditional teaching methods in terms 
of stimulating students' learning interest and enthusiasm and improving teaching efficiency, which is consistent with this study's results.

The primary purpose of a clinical internship is to deepen and consolidate the basic knowledge and cultivate the students' clinical thinking ability so that they can use theoretical knowledge to solve the specific problems encountered in clinical work. The results of this study showed that the BOPPPS model was significantly better than the traditional instructional approach in the aspects of student-teacher interaction, learning initiative, analytical ability, clinical thinking ability, and self-study ability. The experimental group was also significantly better than the control group in the theoretical knowledge examination. Participatory learning is the core part of this teaching model. Teachers can guide students to discuss clinical cases related to the course actively, find problems, and solve problems, effectively improving teaching effectiveness [14]. Additionally, teachers can also obtain feedback information from students in time to adjust subsequent teaching activities. The BOPPPS model can fully inspire students' enthusiasm for studying and guide them to solve problems on their initiative. Simultaneously, it can also improve students' clinical thinking ability and cultivate students' independent learning and communication and cooperation ability. Also, teachers can make continuous progress and improve their teaching methods in teaching activities.

The BOPPPS model is of great help to improve thoracic surgery's teaching quality, but some problems and puzzles need to be further improved in the subsequent instructional practice. First of all, teachers may not inform students of course information promptly before class. There are also significant problems for students' long-term learning effects and review feedback after class. Therefore, in the future BOPPPS teaching promotion, teachers can use the online open curriculum platform constructed by the school to assist BOPPPS teaching. Before class, the learning task is issued through the notification module, the learning materials are uploaded through the learning resource module. After class, teachers can collect feedback from students through the discussion forum module and self-testing module. Secondly, different from traditional theoretical teaching, the BOPPPS model puts forward higher requirements for the teacher, which requires teachers to change the traditional instructor-led teaching concept. The participation of students increases the difficulty of teaching and requires teachers to have high theoretical learning quality and rich clinical practice experience. In the teaching process, teachers need to effectively guide students to explore and solve problems based on their interests. Thirdly, in the practice of the BOPPPS teaching model, we find that teachers still need to explain the theoretical or abstract teaching contents in detail. Therefore, the BOPPPS model should be applied selectively according to the content of the course and based on the students' knowledge background. Finally, the BOPPPS model should be an open instructional design model. Teachers should not stick to the integrity and order of the six modules in instructional practice. We should adjust the instructional design according to the instructional content and students' foundation to make it more in line with students' psychological characteristics and cognitive laws.

\section{Conclusion}


In the present study, we compared the effects of the BOPPPS model and traditional instructional approaches in thoracic surgery teaching. We found that students' overall score in traditional courses was lower than those with the BOPPPS model. The BOPPPS model can stimulate students' interest in thoracic surgery's clinical probation and improve students' problem-solving and clinical analysis abilities. Besides, students can also enhance their communication skills with teachers and patients through teamwork, which will lay a good foundation for future clinical work.

Further rigorous large-sample multicenter studies are needed to confirm whether the BOPPPS model is superior to traditional instructional approaches in overall teaching effectiveness. After continuous exploration and ongoing effort, the BOPPPS model will play a more significant role in medical teaching reform to improve teaching effectiveness and quality.

\section{Abbreviations}

BOPPPS: bridge-in, learning objective, pretest, participatory learning, posttest, and summary

\section{Declarations}

\section{Funding}

The present study was funded by research project of education and teaching reform of Shandong University in 2021 (grant no. 2021Y138), Cheeloo College of Medicine undergraduate teaching reform and research project of Shandong University in 2020 (grant no. qlyxjy-202042) and the first-class undergraduate course construction project of Shandong First Medical University in 2020(grant no. 2020XYK-18).

\section{Conflicts of interest}

The authors declare no conflict of interest.

\section{Availability of data and material}

All data generated or analyzed during this study are included in this published article. The SPSS raw dataset can be provided on request. The corresponding author, Zhi-Gang Sun, will provide additional data, if requested.

\section{Authors' contributions}

Zhi-Gang Sun designed this work. Kang Hu wrote the manuscript. Chao Ma and Qing-Kang Zheng prepared the figures and tables. Rui-Jie Ma drafted and revised the manuscript. All the authors contributed to manuscript revision, read and approved the submitted version.

\section{Acknowledgements}


None

\section{Ethics approval}

All procedures performed in studies involving human participants were in accordance with the ethical standards of the institutional and/or national research committee and with the 1964 Helsinki

Declaration and its later amendments, or comparable ethical standards. The Ethics Committee of Jinan Central Hospital Affiliated to Shandong University has approved conducting this study.

\section{Consent to participate}

Informed consent was obtained from all individual participants included in the study.

\section{Consent for publication}

The participant has consented to the submission of the research to the journal.

\section{References}

1. Etienne H, Hamdi S, Le Roux M, Camuset J, Khalife-Hocquemiller T, Giol M, Debrosse D, Assouad J. Artificial intelligence in thoracic surgery: past, present, perspective and limits. Eur Respir Rev. 2020; 29(157).

2. Lautrette A, Schwebel C, Gruson D, Talbot RW, Timsit JF, Souweine B. Transfer of take-home messages in graduate ICU education. Intensive Care Med. 2011; 37(8):1323-1330.

3. Baum KD, Axtell S. Trends in North American medical education. Keio J Med. 2005; 54(1):22-28.

4. Falk K, Falk H, Jakobsson Ung E. When practice precedes theory - A mixed methods evaluation of students' learning experiences in an undergraduate study program in nursing. Nurse education in practice. 2016; 16(1):14-19.

5. Lam TP, Wan XH, Ip MS. Current perspectives on medical education in China. Med Educ. 2006; 40(10):940-949.

6. Schwarz MR, Wojtczak A, Zhou T. Medical education in China's leading medical schools. Med Teach. 2004; 26(3):215-222.

7. Boroumand S, Stein MJ, Jay M, Shen JW, Hirsh M, Dharamsi S. Addressing the health advocate role in medical education. BMC Med Educ. 2020; 20(1):28.

8. Bi M, Zhao Z, Yang J, Wang Y. Comparison of case-based learning and traditional method in teaching postgraduate students of medical oncology. Med Teach. 2019; 41(10):1124-1128.

9. Ilkiw JE, Nelson RW, Watson JL, Conley AJ, Raybould HE, Chigerwe M, Boudreaux K. Curricular Revision and Reform: The Process, What Was Important, and Lessons Learned. J Vet Med Educ. 2017; 44(3):480-489. 
10. Dickinson BL, Lackey W, Sheakley M, Miller L, Jevert S, Shattuck B. Involving a real patient in the design and implementation of case-based learning to engage learners. Adv Physiol Educ. 2018; 42(1):118-122.

11. Gunderman RB, Brown BP. Teaching interpersonal and communication skills. Acad Radiol. 2012; 19(12):1589-1590.

12. Pattison P, Russell D. Instructional skills workshop handbook. British Columbia, BC: Instructional skills workshop;2006.

13. Yang Y, You J, Wu J, Hu C, Shao L. The Effect of Microteaching Combined with the BOPPPS Model on Dental Materials Education for Predoctoral Dental Students. J Dent Educ. 2019; 83(5):567-574.

14. Shi J, Knight JK, Chun H, Guild NA, Martin JM. Using Pre-Assessment and In-Class Questions to Change Student Understanding of Molecular Movements. J Microbiol Biol Educ. 2017; 18(1).

\section{Tables}

Table 1. Comparison of testing scores between experimental and control groups

\begin{tabular}{|lllll|}
\hline Group & Control group $(\mathrm{n}=44)$ & Experimental group $(\mathrm{n}=44)$ & $t$ value & $p$ value \\
\hline Final examination score & $76.3636 \pm 10.6402$ & $81.4773 \pm 10.9215$ & 2.225 & 0.029 \\
\hline
\end{tabular}

Table 2 Comprehensive evaluation of two teaching models by two groups of students

\begin{tabular}{|lllll|}
\hline Group & Control $\operatorname{group}(\mathrm{n}=44)$ & Experimental group $(\mathrm{n}=44)$ & $t$ value & $p$ value \\
\hline Course satisfaction & $4.7273 \pm 0.4505$ & $4.9091 \pm 0.2908$ & 2.249 & 0.027 \\
\hline Student-teacher interaction & $3.8182 \pm 0.7241$ & $4.5909 \pm 0.6583$ & 5.238 & 0.001 \\
\hline Learning initiative & $3.8182 \pm 0.6317$ & $4.2727 \pm 0.5852$ & 3.676 & 0.001 \\
\hline Analytical ability & $3.5000 \pm 0.6647$ & $4.000 \pm 0.5283$ & 3.906 & 0.001 \\
\hline Clinical thinking ability & $4.000 \pm 0.4822$ & $4.6136 \pm 0.6893$ & 4.838 & 0.001 \\
\hline Self-study ability & $4.4318 \pm 0.5011$ & $4.8864 \pm 0.3210$ & 5.067 & 0.001 \\
\hline
\end{tabular}

\section{Figures}




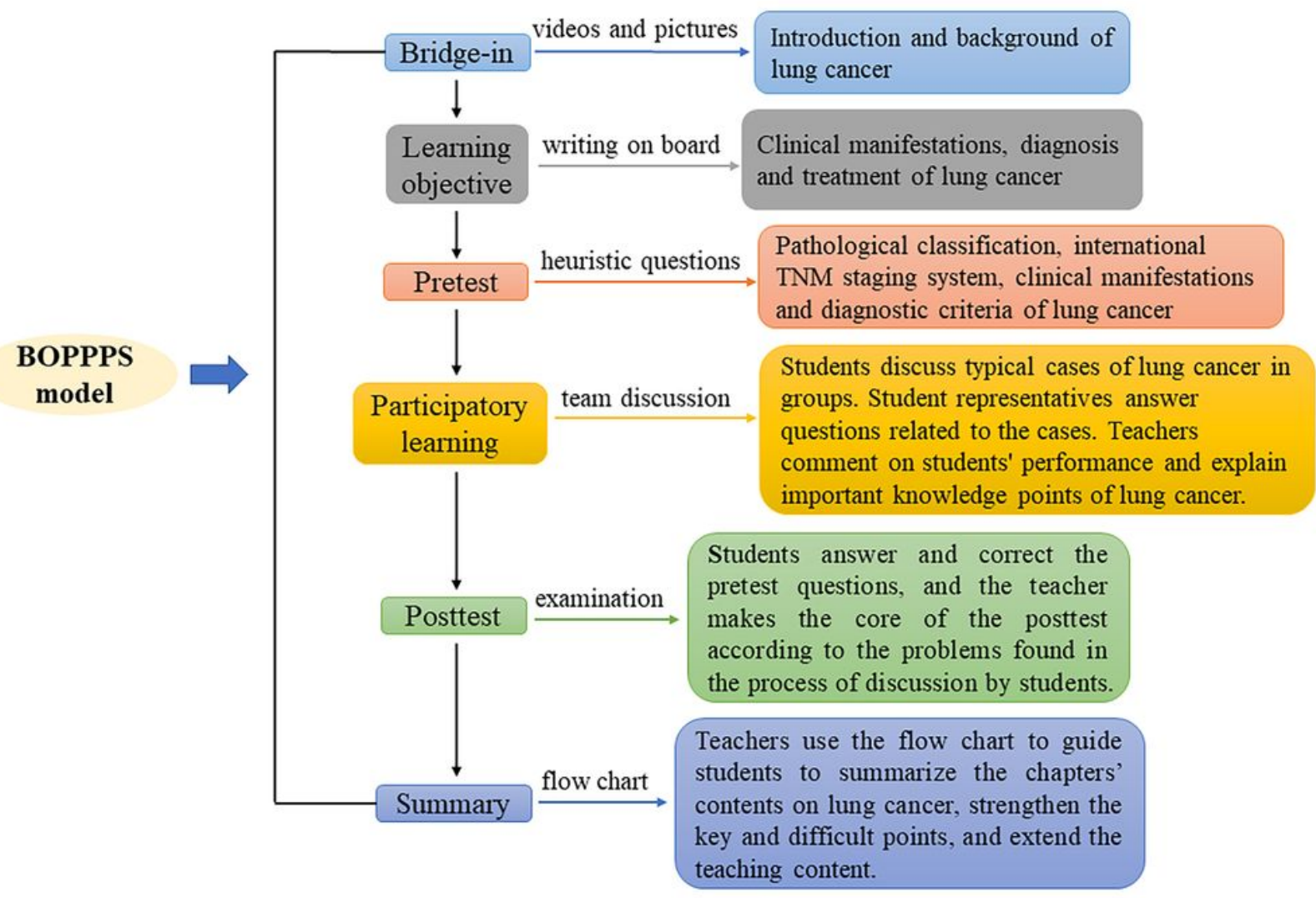

Figure 1

Example of class design for the BOPPPS model

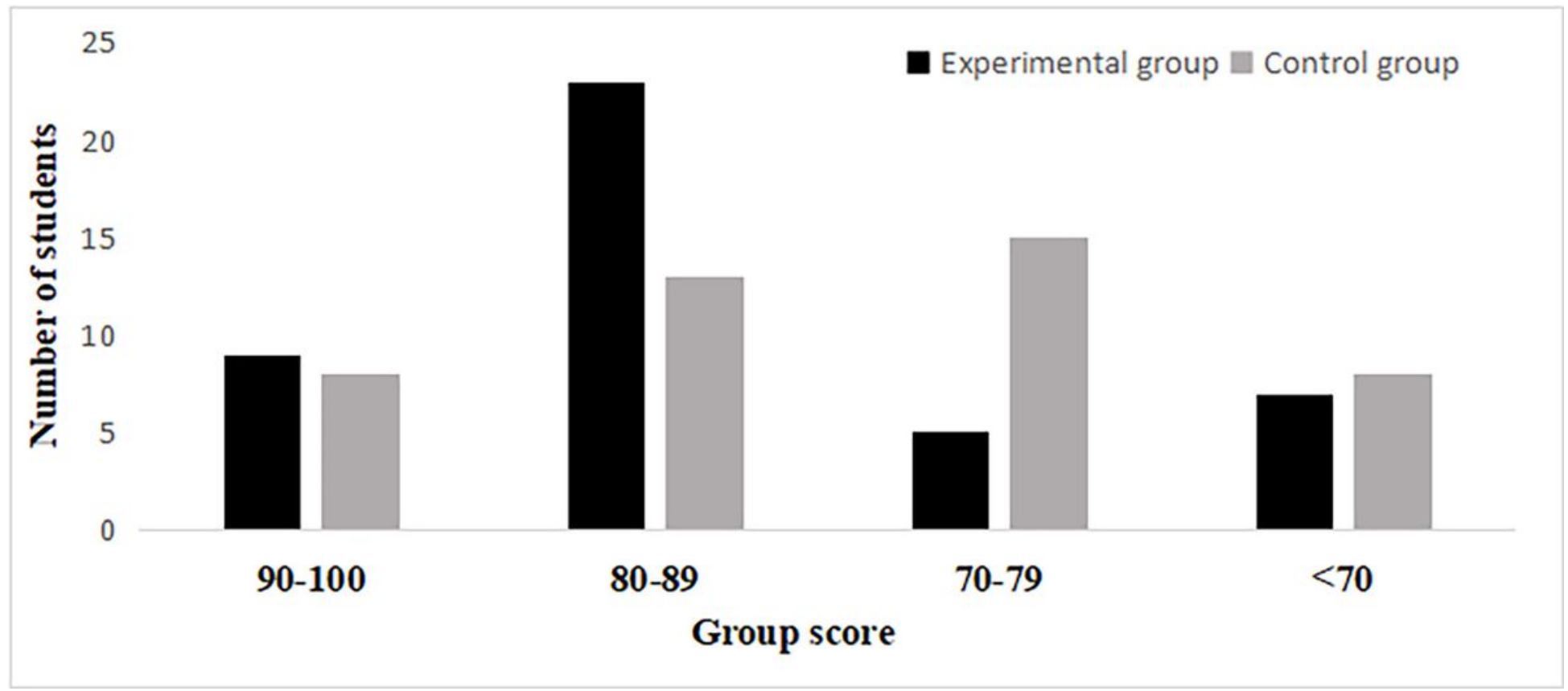

Figure 2

Distribution chart of students' theoretical test scores 


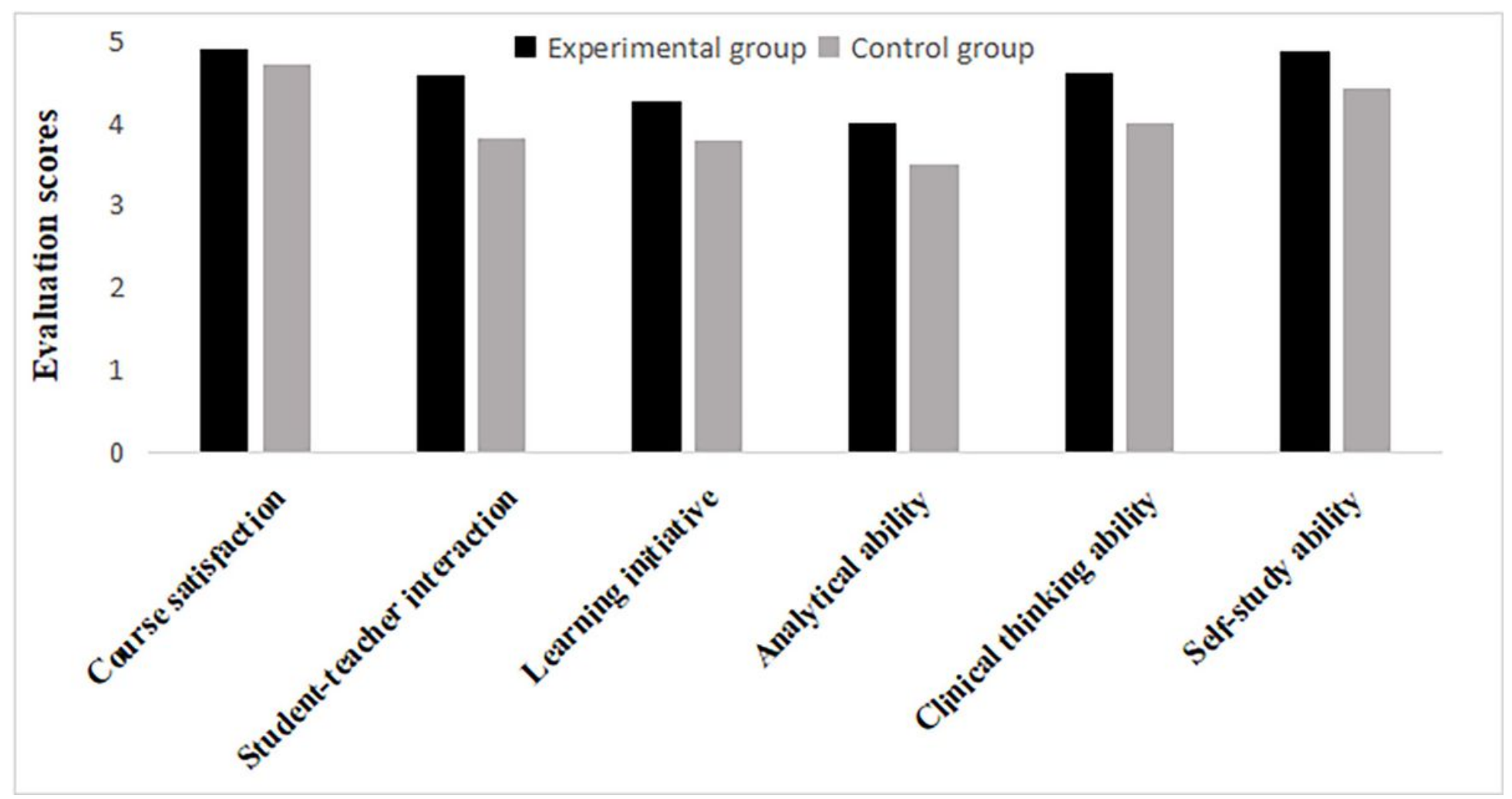

Figure 3

Evaluation of student questionnaire

\section{Supplementary Files}

This is a list of supplementary files associated with this preprint. Click to download.

- SupplementaryMaterialfiguresandtables.docx 